\title{
Occlusal Caries Detection and Diagnosis Using Visual ICDAS Criteria, Laser Fluorescence Measurements, and Near-Infrared Light Transillumination Images
}

\author{
Melek Tassoker $^{a}$ Sevgi Ozcan ${ }^{a}$ Said Karabekiroglu ${ }^{b}$ \\ a Department of Oral and Maxillofacial Radiology, Necmettin Erbakan University, Konya, Turkey;

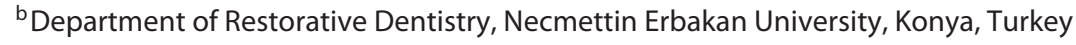

\section{Highlights of the Study}

- This study aimed to compare the performance of visual inspection (ICDAS-II), laser fluorescence (DIAGNOdent pen), and the near-infrared transillumination technique (DIAGNOcam) in the detection of non-cavitated occlusal caries lesions.

- DIAGNOcam was found to be the most effective method for the diagnosis of occlusal caries without cavitation.

\section{Keywords}

Occlusal caries · Near-infrared transillumination · Laser fluorescence $\cdot$ ICDAS-II

\footnotetext{
Abstract

Objective: Current diagnostic tools for non-cavitated occlusal caries are not very reliable. For this reason, newer systems need to be developed. The aim of this study was to compare the performance of visual inspection (ICDAS-II), laser fluorescence (DIAGNOdent pen), and the near-infrared transillumination technique (DIAGNOcam) in the detection of non-cavitated occlusal caries lesions under clinical and laboratory conditions in 90 third molar teeth planned for extraction. Materials and Methods: Ninety third molar teeth were firstly examined in clinical conditions, scored according to ICDAS-II criteria, and examined with DIAGNOdent pen and DIAGNOcam devices. After finishing the clinical examination,
}

the teeth were re-evaluated shortly after the extractions with the same methods. Then, the teeth were sectioned for histological validation according to Downer's criteria. Sensitivity, specificity, accuracy, and area under the receiver operating characteristic (ROC) curves were calculated based on the histological results. Results: For the $D_{0}-D_{1-4}$ threshold, the area under the ROC curve values ranged between 0.754 and 0.881 for all systems. Sensitivity values ranged between 80.5 and $96.1 \%$, and specificity values ranged between 61.5 and $84.6 \%$ for the three caries detection methods. DIAGNOcam had the best correlation value (0.616) according to histological observations and demonstrated a sensitivity rate of $96.1 \%$, a specificity rate of $61.5 \%$, and an accuracy rate of 91.1\%. Conclusions: DIAGNOcam was found to be the most effective method for the diagnosis of occlusal caries without cavitation in permanent molar teeth.

(C) 2019 The Author(s)

Published by S. Karger AG, Basel

\begin{tabular}{|c|c|c|}
\hline KARGER & $\begin{array}{l}\text { (c) } 2019 \text { The Author(s) } \\
\text { Published by S. Karger AG, Basel }\end{array}$ & $\begin{array}{l}\text { Karger } \\
\text { Open access }\end{array}$ \\
\hline $\begin{array}{l}\text { E-Mail k } \\
\text { www.ka }\end{array}$ & $\begin{array}{l}\text { This is an Open Access article licensed } \\
\text { Attribution-NonCommercial- } 4.0 \text { Inte } \\
\text { (http://www.karger.com/Services/Ope } \\
\text { the online version of the article only. } L \\
\text { mercial purposes requires written per }\end{array}$ & $\begin{array}{l}\text { the Creative Commons } \\
\text { al License (CC BY-NC) } \\
\text { sLicense), applicable to } \\
\text { d distribution for com- }\end{array}$ \\
\hline
\end{tabular}

Melek Tassoker

Department of Oral and Maxillofacial Radiology

Faculty of Dentistry, Necmettin Erbakan University

Konya, TR-42050 Konya (Turkey)

E-Mail dishekmelek@gmail.com 


\section{Introduction}

Occlusal caries is most frequent on molar and premolar teeth [1]. The detection of occlusal caries is difficult due to the complex morphology of the occlusal surface [2, $3]$.Visual examination is useful only in more pronounced stages of this caries [2]. Evidence-based new visual criteria for caries detection were developed in 2002 to correlate the clinical status of the teeth with their histopathological status, called the International Caries Detection and Assessment System (ICDAS) [2,4]. Later, a modification was applied and the ICDAS-II criteria was created. ICDAS-II provides a standardization in data collection and comparability among studies and has good reproducibility and accuracy in detecting occlusal caries [4]. Although convenient methods have been developed, it should be noted that visual examination is subjective and depends on observer's decision [5].

Recently, various caries detection systems, such as DIAGNOdent pen (KaVo, Biberach, Germany) and DIAGNOcam (KaVo) have been introduced to improve the accuracy of detecting non-cavitated occlusal caries [6]. DIAGNOdent pen uses laser fluorescence (LF) technology and provides numerical values from 0 to $99[5,7,8]$. This device has been used in various studies for the detection of occlusal and smooth surface caries [3]. It can also be used for proximal surfaces [6]. Higher values indicate deeper caries lesions $[5,8]$. Increased pore volume in demineralized enamel leads to changes in its optical characteristics. LF detects more fluorophores within these pores compared to healthy unchanged enamel [9]. In other words, LF measures the fluorescence of the lesion, the porphyrins which are produced by microbial metabolic products $[5,10]$. The DIAGNOdent pen emits a red diode laser beam and the procedure requires the device to be in contact with the lesion [10]. It is the most widely used LFbased device for detecting caries and is advised in some studies as a diagnostic system adjunct to dental radiographs [11]. Shi et al. [12] showed that LF was significantly more effective than radiographs in detecting occlusal caries. DIAGNOcam (KaVo) uses near-infrared (NIR) light $(780 \mathrm{~nm})$ for detecting caries. This system is based on digital fiber optical transillumination (DIFOTI) [13]. The major difference between the two is that DIFOTI uses visible light, while NIR light transillumination (NIR-LT) uses invisible long-wave light [14]. Recently published studies show that NIR-LT is suitable for detecting early caries lesions [15].

The detection of occlusal caries, especially hidden caries, is quite difficult and there is a great variation between clinicians' diagnoses. Non-cavitated caries is more common than visible cavitated caries [16] due to the widespread use of fluoride [17]. Additional X-ray free diagnostic tools may help to provide more consistent decisions. There are numerous ICDAS studies, many DIAGNOdent studies, but only a few DIAGNOcam studies on occlusal surfaces $[6,13,17]$. The aim of this study was to evaluate the capability of DIAGNOcam in detecting non-cavitated occlusal caries lesions and to compare it with visual inspection (ICDAS-II) and LF under clinical and laboratory conditions in 90 third molar teeth planned for extraction. To our knowledge, no other studies have been reported comparing these three systems in the detection of non-cavitated occlusal caries with histological validation.

\section{Material and Methods}

Study Population and Design

This study was conducted between December 2017 and April 2018 in the Department of Conservative Dentistry, Faculty of Dentistry, Necmettin Erbakan University. A total of 90 third molar teeth planned for extraction were selected from 90 patients with a mean age of 23 years (range 18-25). DMFT (decayed-missingfilled teeth) scores of the individuals were between 4 and 15 . Inclusion of the individuals was according to the following criteria: fully erupted permanent dentition, no orthodontic treatment with fixed appliances, and minimum age of 18 years. The third molar teeth were non-cavitated, non-hypoplastic, and they had no restorations or fissure sealants.

As a result of the power analysis performed on a sample size of $n=90$, an actual power of $0.812,5 \%$ type-I error and $80 \%$ prevalence, was found, and based on this 90 third molar teeth were satisfactory. The teeth were firstly examined in clinical conditions and scored according to ICDAS-II criteria and examined with DIAGNOdent pen and DIAGNOcam devices. After finishing the clinical examination, the teeth were re-evaluated shortly after the extractions with the same methods and in the same order. Then, the teeth were sectioned for histological validation according to Downer's [18] criteria.

\section{Visual Examination}

For visual inspection, the teeth were initially professionally cleaned using a rotary brush and a low abrasive polishing paste, and then the lesion severity was scored according to ICDAS-II system. The visual inspection was conducted with a blunt probe, dental mirror, and the light source of the dental unit. No visual aids such as microscopes or magnifying glasses were used. The teeth were examined after drying with compressed air for $5 \mathrm{~s}$. The advanced scoring in ICDAS-II intended for more advanced caries lesions was not used because it is not relevant to our study (Table 1).

\section{LF Measurements}

The application of the DIAGNOdent pen (KaVo 2190, wavelength $655 \mathrm{~nm}$ ) was according to the manufacturer's instructions, which recommended the tooth to be primarily isolated with cotton 
Table 1. Distribution of the caries extent according to ICDAS-II, DIAGNOdent pen, DIAGNOcam, and Downer's histological criteria

\begin{tabular}{|c|c|c|c|}
\hline $\begin{array}{l}\text { Visual (ICDAS-II) } \\
(n=90)\end{array}$ & $\begin{array}{l}\text { LF (DIAGNOdent pen) } \\
(n=90)\end{array}$ & $\begin{array}{l}\text { NIR-LT (DIAGNOcam) } \\
(n=90)\end{array}$ & $\begin{array}{l}\text { Histological } \\
(n=90)\end{array}$ \\
\hline $0=$ Healthy & $\begin{array}{l}0:<10=\text { healthy tooth } \\
\text { structure }\end{array}$ & $\begin{array}{l}0=\text { healthy (light transmission } \\
\text { unchanged) }\end{array}$ & $\begin{array}{l}\mathrm{D}_{0}=\text { no enamel demineralization or } \\
\text { opacity on small surface areas }\end{array}$ \\
\hline $1=$ First visual change in enamel & $\begin{array}{l}\text { 1: } 10-14=\text { outer half of } \\
\text { enamel caries }\end{array}$ & $1=$ enamel/dentine decay & $\begin{array}{l}\mathrm{D}_{1}=\text { demineralization limited to outer } \\
\text { half of the enamel layer }\end{array}$ \\
\hline $2=$ Distinct visual change in enamel & $\begin{array}{l}\text { 2: } 15-20=\text { inner half of } \\
\text { enamel caries }\end{array}$ & $\begin{array}{l}\text { (shadow visible in the enamel/ } \\
\text { dentine) }\end{array}$ & $\begin{array}{l}\mathrm{D}_{2}=\text { demineralization involving the } \\
\text { inner half of enamel, up to the enamel- } \\
\text { dentine junction }\end{array}$ \\
\hline $\begin{array}{l}3=\text { Localized enamel breakdown, } \\
\text { no dentine visible }\end{array}$ & $\begin{array}{l}\text { 3: } 21-30=\text { initial dentine } \\
\text { lesions }\end{array}$ & & $\begin{array}{l}\mathrm{D}_{3}=\text { demineralization involving the } \\
\text { external half of dentine }\end{array}$ \\
\hline $\begin{array}{l}\text { The advanced scoring for the ICDAS-II } \\
\text { system is not suitable for our sample }\end{array}$ & $\begin{array}{l}\text { 4: } \geq 31 \text { = advanced dentine } \\
\text { lesions }\end{array}$ & & $\begin{array}{l}\mathrm{D}_{4}=\text { demineralization involving internal } \\
\text { half of dentine }\end{array}$ \\
\hline
\end{tabular}

LF, laser fluorescence; NIR-LT, near-infrared light transillumination.

rolls followed by drying for $5 \mathrm{~s}$. The tip of the device was placed vertically into the pits and fissures to get the highest fluorescence value. After the application the values were evaluated (Table 1).

\section{NIR-LT}

DIAGNOcam (KaVo 2170, wavelength $780 \mathrm{~nm}$ ) examination was carried out with the dental unit light source off, on dried and cleaned tooth surfaces. The presence and absence of caries was diagnosed. During the procedure the images were not archived. Carious changes are displayed as dark shades in contrast to the healthy tooth substances and were scored as follows:

0 - light transmission unchanged

1 - shadow visible in the enamel/dentine.

After the extractions the teeth were cleaned to remove blood residues and stored in distilled water. This is because distilled water provides standardization in fluorescence measurements. For in vitro evaluations, teeth were stabilized in acrylic resin blocks. Then, caries assessment was performed with all methods independently by the same examiner. All diagnoses were blindly made from all the other diagnostic results, which resulted in an independent and unbiased diagnostic conclusion. The in vitro DIAGNOdent pen and DIAGNOcam examinations were performed as described in in vivo examination.

\section{Histological Examination (Reference Standard)}

The teeth were placed in acrylic molds for histological evaluation. Then, using an Isomet precision sectioning saw under water cooling conditions, they were divided into 300 - to $400-\mu \mathrm{m}$ slices in the mesiodistal direction with diamonds spare, passing through the center of the measurement point and parallel to the longitudinal axis of the tooth. The section where the decay was deeper was selected for evaluation. There was no tooth loss during this sectioning. For histological evaluation, the slices were examined with an Olympus SZ4045 TRPT stereomicroscope at a 40× magnification rate. Evaluation of the sections examined under the microscope was made in compliance with Downer's [18] histological scoring criteria (Table 1).

\section{Calibration}

This study was performed by 1 examiner (S.K.) and had two phases which were an in vitro and in vivo phase. The operator (S.K.) made all diagnostic decisions and histological examinations. In order to calculate intra-observer reliability, the operator of the study had been calibrated on 25 teeth before performing the diagnostic methods $(\kappa=0.76-0.91)$. All samples were prepared and evaluated by the same examiner who had 4 years of experience in conservative dentistry. The researchers who conceived this study had previously conducted research projects and doctoral theses in the same topic and have a minimum of 3 years of experience with each diagnostic system (ICDAS-II, DIAGNOdent pen, and DIAGNOcam).

\section{Statistics}

In this study, the histological evaluation method which was used to assess the efficacy of different methods that we used for diagnosing occlusal decay was accepted as the "reference standard." The data that we have obtained were evaluated by grouping according to the threshold values of $\mathrm{D}_{1}$ (solid-decay differentiation), $\mathrm{D}_{2}$ (enamel decay), and $\mathrm{D}_{3}$ (dentine decay; Table 2). According to the threshold value range of $D_{1}$, a score of 0 was determined as healthy tooth and scores of 1,2 , and 3 as decayed tooth. According to the threshold value range of $\mathrm{D}_{2}$, scores of 0 and 1 were accepted as healthy tooth, and scores of 2 and 3 as decayed tooth. According to the threshold value range of $\mathrm{D}_{3}$, scores of 0,1 , and 2 were accepted as healthy tooth, while a score of 3 was accepted as decayed tooth.

Sensitivity, specificity, accuracy, and area under the receiver operating characteristic (ROC) curves were calculated based on histological reference standards. The analyses were performed by SPSS v.21.0 (IBM Corp, Armonk, NY, USA), PASS (v.13.0.6, NCSS, LLC, Kaysville, UT, USA), and STATA (v.14.2, 2015, StataCorp, College Station, TX, USA). The significance level was $p<$ 0.05 . 
Table 2. Threshold values

\begin{tabular}{lllll}
\hline $\begin{array}{l}\text { Caries detection } \\
\text { methods }\end{array}$ & Healthy & $\begin{array}{l}\text { Solid-decay } \\
\text { differentiation }\end{array}$ & $\begin{array}{l}\text { Enamel } \\
\text { decay }\end{array}$ & $\begin{array}{l}\text { Dentine } \\
\text { decay }\end{array}$ \\
\hline Histology & $\mathrm{D}_{0}$ & $\mathrm{D}_{1}$ & $\mathrm{D}_{2}$ & $\mathrm{D}_{3}$ \\
ICDAS-II & 0 & 1 & 2 & 3 \\
DIAGNOdent pen & 0 & 1 & 2 & $3-4$ \\
DIAGNOcam & 0 & 1 & 1 & 1 \\
\hline
\end{tabular}

Table 3. The distribution of the sample according to histological thresholds

\begin{tabular}{ll}
\hline Histological threshold & Frequency, $n(\%)$ \\
\hline $\mathrm{D}_{0}$ & $13(14.4)$ \\
$\mathrm{D}_{1}$ & $18(20)$ \\
$\mathrm{D}_{2}$ & $18(20)$ \\
$\mathrm{D}_{3}$ & $20(22.2)$ \\
$\mathrm{D}_{4}$ & $21(23.3)$ \\
\hline Total & $90(100)$ \\
\hline
\end{tabular}

\section{Results}

Of the 90 samples, $14.4 \%$ had no caries lesions according to Downer's [18] histological criteria. The distribution of the samples according to their histological thresholds are given in Table 3.

We observed that the DIAGNOcam had the best correlation value (0.608) with the histological reference standard and demonstrated a sensitivity rate of $96.1 \%$, specificity rate of $61.5 \%$, and an accuracy rate of $91.1 \%$. In vitro evaluation results demonstrated higher sensitivity and specificity rates compared to in vivo evaluations. All methods had comparatively high areas under the ROC curve. The sensitivity, specificity, accuracy, area under the ROC curve values, and the correlation coefficients of the histological results of the three methods are shown in Tables 4 and 5.

The intra-observer consistency was always $>0.94$. Kendall's tau correlation coefficients of the caries diagnostic methods are presented in Table 6.

\section{Discussion}

This is the first study to include both an in vivo and in vitro component using ICDAS-II, LF, and NIR-LT methods with reference to histological validation and analysis of their performance to predict the presence of non-cavitated occlusal caries lesions in permanent third molars. The major limitation in many studies is the histological validation of the results. In this study, this limitation was overcome by planning extraction of the teeth. In vivo studies evaluating caries detection have a disadvantage in terms of validating the results if operative/invasive treatment is not planned. In vitro studies permit histopathological validation to assess the extent of the decay more accurately [19].

There are numerous studies in the literature investigating the performance of diagnostic systems for caries detection. Some of the differences in the results can be related to the storage conditions, presence of discolorations, calculus, plaque, and remnants of prophylaxis pastes. These may all influence the measurements and lead to false-positive results [2].

The accurate diagnosis of occlusal caries is still challenging [6] and the early diagnosis of occlusal caries plays an important role in dental practice. The occlusal fissure structure should be examined regularly for signs of caries because of its susceptibility to caries [9]. Visual inspection may misinterpret the extent of non-cavitated occlusal caries [3]. However, it is important to be able to detect such lesions to help treatment decisions. A correct diagnosis leads to the application of proper preventive measures or operative procedures [9]. It was observed that the earlier the stage of the decay, the worse the performance of the method [8].

Between the three methods used, our results revealed that in vitro DIAGNOcam findings were most closely correlated to the histological results and presented the highest sensitivity and accuracy rates at the $\mathrm{D}_{1}$ threshold. This means that DIAGNOcam is the most effective method in discriminating healthy and carious lesions. According to the threshold value range in $\mathrm{D}_{2}$ and $\mathrm{D}_{3}$, DIAGNOdent had higher sensitivity rates than ICDAS-II. Without taking the examination conditions into consideration, the in vitro evaluation results demonstrated higher sensitivity and specificity rates compared to in vivo evaluations. At the threshold of $\mathrm{D}_{1}$, the DIAGNOcam device showed significantly better sensitivity rates compared to the other methods, but lower specificity rates. Therefore, compared to other methods, this device seems to be able to detect caries lesions at an earlier phase, but has high rates in misconceiving healthy tooth surfaces as carious. The diagnostic accuracy of the DIAGNOcam method was further aided by a greater area under the ROC curve. The DIAGNOcam device was more sensitive than ICDAS-II to early changes in enamel, but had lower specificity rates. 
Table 4. The sensitivity and specificity rates of ICDAS-II and DIAGNOdent at different thresholds

\begin{tabular}{|c|c|c|c|c|c|c|c|c|c|c|c|c|}
\hline \multirow{3}{*}{$\begin{array}{l}\text { Caries } \\
\text { detection }\end{array}$} & \multicolumn{4}{|l|}{$\underline{\mathrm{D}_{1}}$} & \multicolumn{4}{|l|}{$\mathrm{D}_{2}$} & \multicolumn{4}{|l|}{$\mathrm{D}_{3}$} \\
\hline & \multicolumn{2}{|l|}{ sensitivity } & \multicolumn{2}{|l|}{ specificity } & \multicolumn{2}{|l|}{ sensitivity } & \multicolumn{2}{|l|}{ specificity } & \multicolumn{2}{|l|}{ sensitivity } & \multicolumn{2}{|l|}{ specificity } \\
\hline & ICDAS-II & DIAGNOdent & ICDAS-II & DIAGNOdent & ICDAS-II & DIAGNOdent & ICDAS-II & DIAGNOdent & ICDAS-II & DIAGNOdent & ICDAS-II & DIAGNOdent \\
\hline In vivo & 85.71 & 80.52 & 84.61 & 76.92 & 42.86 & 67.53 & 92.31 & 76.92 & 24.68 & 51.95 & 100.00 & 76.92 \\
\hline In vitro & 87.01 & 92.21 & 84.62 & 76.92 & 48.05 & 79.22 & 92.31 & 84.62 & 24.68 & 59.74 & 92.31 & 92.31 \\
\hline
\end{tabular}

Table 5. The sensitivity, specificity, and area under the ROC curve values and correlation coefficients of the histological results of the three methods at $\mathrm{D}_{1}$ threshold

\begin{tabular}{|c|c|c|c|c|c|}
\hline Caries diagnosis systems & $\begin{array}{l}\text { Sensitivity, } \\
\%\end{array}$ & $\begin{array}{l}\text { Specificity, } \\
\%\end{array}$ & $\begin{array}{l}\text { Accuracy, } \\
\%\end{array}$ & $\begin{array}{l}\text { Correlation } \\
\text { coefficient of } \\
\text { the histological } \\
\text { results }\end{array}$ & $\begin{array}{l}\text { The area under the } \\
\text { ROC curve }\end{array}$ \\
\hline ICDAS-II (in vivo) & 85.7 & 84.6 & 85.5 & 0.540 & 0.861 \\
\hline ICDAS-II (in vitro) & 87.0 & 84.6 & 86.6 & 0.534 & 0.852 \\
\hline DIAGNOdent (in vivo) & 80.5 & 76.9 & 80.0 & 0.443 & 0.754 \\
\hline DIAGNOcam (in vivo) & 93.5 & 69.2 & 90.0 & 0.608 & 0.813 \\
\hline DIAGNOcam (in vitro) & 96.1 & 61.5 & 91.1 & 0.616 & 0.788 \\
\hline
\end{tabular}

Table 6. Kendall's tau correlation coefficients of caries diagnosis methods

\begin{tabular}{llll}
\hline & $\begin{array}{l}\text { ICDAS-II } \\
\text { (in vitro) }\end{array}$ & $\begin{array}{l}\text { DIAGNOdent } \\
\text { (in vitro) }\end{array}$ & $\begin{array}{l}\text { DIAGNOcam } \\
\text { (in vitro) }\end{array}$ \\
\hline ICDAS-II (in vivo) & 0.944 & 0.542 & - \\
DIAGNOdent (in vivo) & 0.547 & 0.724 & - \\
DIAGNOcam (in vivo) & - & - & 0.861 \\
\hline
\end{tabular}

Because of this, this study recommended that at the $\mathrm{D}_{1}$ threshold DIAGNOcam images are more precise than other methods. In this study, the DIAGNOcam specificity rates for in vivo evaluations were slightly higher than for the in vitro evaluations, which could be due to the differences in the oral cavity and the in vitro environmental conditions.

Only a few studies have evaluated the diagnostic performance of DIAGNOcam and our results support that this device could be used effectively for the detection of occlusal caries without cavitation. Marinova-Takorova et al. [6] found that DIAGNOcam was more sensitive than radiographic examination intended for occlusal caries diagnosis. In the samples where only the enamel was affected, the visual diagnostic method showed a sensitivity rate of $23.4 \%$ which was accepted as insufficient. The ra-

Caries Diagnosis Using Different Methods diographic diagnosis of the caries lesions is accurate when the dentine is involved, however it generally leads to a misinterpretation of the extent of the caries when only the enamel is affected [6].

Valera et al. [20] indicated that visual examination has a low sensitivity but high specificity. The fundamentals of this method are closely associated to the opacity of the occlusal surfaces. It is a highly subjective technique and requires experience. The sensitivity of the visual method ranges from 0.30 to 0.80 and its specificity from 0.70 to 0.90 [6]. The calculated specificity (84.6\%) and sensitivity $(85.7-87 \%)$ rates in this study were good. This may be because of the observer's experience in studies conducted on the diagnoses of dental caries [9]. Bengtson et al. [21] suggested that the observers' clinical experience is important for caries detection in terms of visual examination. Valera et al. [20] also found that visual and radiographic examination made together for occlusal caries resulted in specificity rates of $99 \%$. The combination of visual and tactile methods provides a more accurate diagnosis, but the need to use a probe is a drawback [6].

False negative cases are hidden occlusal caries lesions which penetrate into dentine but cannot be seen macroscopically [9]. Therefore, DIAGNOdent pen and DIAGNOcam might be useful in detecting hidden occlusal caries. Huth et al. [9] found that LF was excellent (area under 
the ROC curve 0.92) in discriminating healthy and carious lesions and good (area under the ROC curve 0.78) in discriminating enamel and dentine caries. Lederer et al. [22] found that DIAGNOcam was more capable of detecting initial proximal lesions than digital radiography.

Many studies have reported high sensitivity rates for LF, ranging from 79 to $100 \%[3,23,24]$. When comparing LF with visual methods for occlusal caries, Braga et al. [5] found that for LF specificity was higher than the visual method. Our results indicated that LF (area under the ROC curve 0.75-0.88) and a visual method (area under the ROC curve $0.85-0.86$ ) were good in discriminating healthy and carious lesions. On the other hand, Ricketts [25] reported that DIAGNOdent showed greater sensitivity but poorer specificity than the visual method and recommended this technique as an adjunct method.

Early and accurate diagnosis has vital importance in planning the treatment. In this study we considered visual, LF, and NIR-LT methods. One of the interesting results of our study was the decrease in sensitivity rates at the $\mathrm{D}_{3}$ level for visual examination (ICDAS-II). This can be explained with our study sample because only teeth with non-cavitated caries were included in the study. Although normal dentine caries lesions are easier to detect by visual inspection, diagnosis may become difficult if the teeth have an intact enamel surface.

Because occlusal surfaces of permanent third molar teeth were investigated, uncommon occlusal surface structure, variations in eruption angle, restricted light, and intraoral access during investigation with the visual method were limitations of this study. Especially the third molar teeth in the study that were not in an upright posi- tion can be thought to not reflect the entire sample. However, for ethical reasons, it has been identified as the best method for histological verification for caries classification on these permanent teeth. It should be stated that the existence of caries lesions in third molars is uncommon. The third molar teeth have an occlusal morphology similar to other molar teeth, which provides a suitable environment for plaque accumulation and subsequent caries lesion formation.

\section{Conclusion}

Within the limitations of this study, the NIR-LT method is recommended above all in the discrimination of healthy and occlusal carious lesions. LF was found to be a more sensitive method for discriminating enamel and dentine caries compared to the visual technique.

\section{Statement of Ethics}

This study was approved by the Ethics Committee of the Necmettin Erbakan University, Faculty of Dentistry (decision No. 2017/12) and written informed consent was obtained from all the patients. All procedures followed were in accordance with the ethical standards of the responsible committee on human experimentation (institutional and national) and with the Helsinki Declaration of 1975, as revised in 2008.

\section{Disclosure Statement}

The authors declare that they have no conflicts of interest.

\section{References}

1 Melo M, Pascual A, Camps I, Del Campo Á. In vivo study of different methods for diagnosing pit and fissure caries. J Clin Exp Dent. 2015 Jul;7(3):e387-91.

2 Achilleos EE, Rahiotis C, Kakaboura A, Vougiouklakis G. Evaluation of a new fluorescence-based device in the detection of incipient occlusal caries lesions. Lasers Med Sci. 2013 Jan;28(1):193-201.

3 Lussi A, Hellwig E. Performance of a new laser fluorescence device for the detection of occlusal caries in vitro. J Dent. 2006 Aug;34(7):467-71.

4 Diniz MB, Rodrigues JA, Hug I, Cordeiro RC, Lussi A. Reproducibility and accuracy of the ICDAS-II for occlusal caries detection. Community Dent Oral Epidemiol. 2009 Oct;37(5): 399-404.
5 Braga MM, de Benedetto MS, Imparato JC, Mendes FM. New methodology to assess activity status of occlusal caries in primary teeth using laser fluorescence device. J Biomed Opt. 2010 Jul-Aug;15(4):047005.

6 Marinova-Takorova M, Panov V, Anastasova R. Effectiveness of near-infrared transillumination in early caries diagnosis. Biotechnol Biotechnol Equip. 2016;30(6):1207-11.

7 Lee Y. Diagnosis and Prevention Strategies for Dental Caries. J Lifestyle Med. 2013 Sep; 3(2):107-9.

8 Mendes FM, Siqueira WL, Mazzitelli JF, Pinheiro SL, Bengtson AL. Performance of DIAGNOdent for detection and quantification of smooth-surface caries in primary teeth. J Dent. 2005 Jan;33(1):79-84.
9 Huth KC, Neuhaus KW, Gygax M, Bücher K, Crispin A, Paschos E, et al. Clinical performance of a new laser fluorescence device for detection of occlusal caries lesions in permanent molars. J Dent. 2008 Dec;36(12):103340.

10 Seremidi K, Lagouvardos P, Kavvadia K. Comparative in vitro validation of VistaProof and DIAGNOdent pen for occlusal caries detection in permanent teeth. Oper Dent. 2012 May-Jun;37(3):234-45.

11 Najeeb S, Khurshid Z, Zafar MS, Ajlal S. Applications of Light Amplification by Stimulated Emission of Radiation (Lasers) for Restorative Dentistry. Med Princ Pract. 2016; 25(3):201-11. 
12 Shi XQ, Welander U, Angmar-Månsson B. Occlusal caries detection with KaVo DIAGNOdent and radiography: an in vitro comparison. Caries Res. 2000 Mar-Apr;34(2):151-8.

13 Schaefer G, Pitchika V, Litzenburger F, Hickel R, Kühnisch J. Evaluation of occlusal caries detection and assessment by visual inspection, digital bitewing radiography and nearinfrared light transillumination. Clin Oral Investig. 2018 Sep;22(7):2431-8.

14 Baltacioglu IH, Orhan K. Comparison of diagnostic methods for early interproximal caries detection with near-infrared light transillumination: an in vivo study. BMC Oral Health. 2017 Nov; 17(1):130.

15 Elhennawy K, Askar H, Jost-Brinkmann PG, Reda S, Al-Abdi A, Paris S, et al. In vitro performance of the DIAGNOcam for detecting proximal carious lesions adjacent to composite restorations. J Dent. 2018 May;72:39-43.

16 Ozkan G, Guzel KG. Clinical evaluation of near-infrared light transillumination in approximal dentin caries detection. Lasers Med Sci. 2017 Aug;32(6):1417-22.
17 Simon JC, Kang H, Staninec M, Jang AT, Chan KH, Darling CL, et al. Near-IR and CPOCT imaging of suspected occlusal caries lesions. Lasers Surg Med. 2017 Mar;49(3):21524.

18 Downer MC. Concurrent validity of an epidemiological diagnostic system for caries with the histological appearance of extracted teeth as validating criterion. Caries Res. 1975;9(3): 231-46.

19 Reis A, Mendes FM, Angnes V, Angnes G, Grande RH, Loguercio AD. Performance of methods of occlusal caries detection in permanent teeth under clinical and laboratory conditions. J Dent. 2006 Feb;34(2):89-96.

20 Valera FB, Pessan JP, Valera RC, Mondelli J, Percinoto C. Comparison of visual inspection, radiographic examination, laser fluorescence and their combinations on treatment decisions for occlusal surfaces. Am J Dent. 2008 Feb;21(1):25-9.

21 Bengtson AL, Gomes AC, Mendes FM, Cichello LR, Bengtson NG, Pinheiro SL. Influence of examiner's clinical experience in detecting occlusal caries lesions in primary teeth. Pediatr Dent. 2005 May-Jun;27(3):23843.
22 Lederer A, Kunzelmann KH, Heck K, Hickel $\mathrm{R}$, Litzenburger $\mathrm{F}$. In vitro validation of nearinfrared transillumination at $780 \mathrm{~nm}$ for the detection of caries on proximal surfaces. Clin Oral Investig. 2019. DOI: https://doi. org/10.1007/s00784-019-02824-0. Epub ahead of print.

23 Bader JD, Shugars DA. A systematic review of the performance of a laser fluorescence device for detecting caries. J Am Dent Assoc. 2004 Oct;135(10):1413-26.

24 Rechmann P, Charland D, Rechmann BM, Featherstone JD. Performance of laser fluorescence devices and visual examination for the detection of occlusal caries in permanent molars. J Biomed Opt. 2012 Mar; 17(3): 036006.

25 Ricketts D. The eyes have it. How good is DIAGNOdent at detecting caries? Evid Based Dent. 2005;6(3):64-5. 